\title{
Risk factors for positive sentinel lymph node, lymphatic or hematogenous dissemination over time in patients with cutaneous melanoma
}

\author{
ALEXANDRA S. BERGHE ${ }^{1 *}$, GHEORGHE COBZAC ${ }^{2 *}$, GEORGE DINDELEGAN ${ }^{3 *}$, SIMONA C. ȘENILA $^{4}$, \\ CORINA I. BAICAN ${ }^{4}$, CAROLINA M. SOLOMON ${ }^{5}$, LILIANA ROGOJAN ${ }^{6}$, \\ DANIEL C. LEUCUȚA ${ }^{1}$, TUDOR C. DRUGAN ${ }^{1}$ and SORANA D. BOLBOACĂ ${ }^{1}$ \\ ${ }^{1}$ Department of Medical Informatics and Biostatistics, 'Iuliu Hațieganu’ University of Medicine and Pharmacy,
400349 Cluj-Napoca; ${ }^{2}$ Department of Nuclear Medicine, County Emergency Hospital Cluj-Napoca;
Departments of ${ }^{3}$ Surgery I, ${ }^{4}$ Dermatology and ${ }^{5}$ Radiology, 'Iuliu Hatieganu' University of
Medicine and Pharmacy, County Emergency Hospital Cluj-Napoca; ${ }^{6}$ Department of Pathology,
County Emergency Hospital Cluj-Napoca, 400006 Cluj-Napoca, Romania
}

Received February 19, 2021; Accepted March 23, 2021

DOI: $10.3892 / \mathrm{etm} .2021 .10162$

\begin{abstract}
The aim of the present study was to assess the influence of localization, age or sex and histopathological characteristics upon the chance of developing lymphatic or hematogenous metastatic spread over time, or a positive sentinel lymph node in cutaneous melanoma patients. Patients from the Department of Dermatology, County Emergency Hospital Cluj-Napoca (Cluj-Napoca, Romania), presenting with cutaneous melanoma confirmed histopathologically and a SPECT/CT or lymphoscintigraphic examination to detect the sentinel lymph node, were included in the present study. Our results revealed that Breslow index $>2 \mathrm{~mm}$ [odds ratio $(\mathrm{OR})=4.22,95 \%$ confidence interval $(\mathrm{CI})(1.12 ; 15.93)]$, presence of ulceration [OR=6.01, 95\% CI $(1.87 ; 19.35)]$, and positive sentinel lymph node [for at least one sentinel lymph node $\mathrm{OR}=3.58,95 \%$ CI $(1.06 ; 12.04)]$ were risk factors for hematogenous metastases. All these, except for the Breslow index $>2 \mathrm{~mm}$, were demonstrated to be a risk factor for lymphatic spread metastases over time. Ulceration and male sex also represented risk factors for a positive sentinel lymph node, men having a higher risk of developing sentinel lymph nodes than women [adjusted OR=2.27, 95\% CI $(1.00 ; 5.13)$ ].
\end{abstract}

Correspondence to: $\operatorname{Dr}$ Simona C. Șenilă, Department of Dermatology, 'Iuliu Hațieganu' University of Medicine and Pharmacy, County Emergency Hospital Cluj-Napoca, Street Clinicilor 3-5, 400006 Cluj-Napoca, Romania

E-mail: corina.senila@umfcluj.ro

${ }^{*}$ Contributed equally

Key words: sentinel lymph node, lymphatic metastasis, hematogenous metastasis, risk factors, cutaneous melanoma
In conclusion, the predictors that influence the occurrence of lymphatic or hematogenous metastases may differ, ulceration and positive sentinel lymph node being common for both types of metastatic spread, while Breslow index being a significant predictor only for hematogenous metastases. Male sex and the presence of ulceration were demonstrated to be significant risk factors for positive sentinel lymph nodes.

\section{Introduction}

Melanoma, a malignant tumor derived from melanocytes, which are cells residing mainly in skin, represent up to $5 \%$ of all cutaneous cancers. The incidence and mortality of melanoma are high due to lymphatic and hematogenous metastatic spread (1,2). Out of almost 325,000 new cases in 2020 worldwide, approximately 150,000 of these were only in Europe, with more than 1,500 reported only in Romania (3). The data suggests that the high incidence in Romania could be due to the fact that patients are being diagnosed in advanced stages of disease, with loco-regional and distant metastatic spread at the time of diagnosis (4). Australia and New Zeeland remain the areas with the highest incidence of melanoma. This type of cancer is the third in incidence after prostate and breast cancer in regions with the highest incidence (3).

Several factors could significantly influence the presence of local or distant melanoma metastases. Among these, previous studies have demonstrated that age (5-7), sex (8), Breslow index $(6,7)$, location of lesion $(7)$, and ulceration $(6,7)$ influence the prognosis of loco-regional spread and distant metastases. Older age and male sex are factors that have a negative impact on the prognosis of metastases (5-8). Calomarde-Rees et al reported a hazard ratio (HR) of 1.9 for subjects over 55 years for lymphatic metastases (5). Mervic (8) revealed that the 10 -year probability for developing metastases from the diagnosis of the primary tumor was $22.8 \%$ [95\% confidence 
interval (CI) $(20.9 ; 24.7)]$, where $95 \%$ CI denoted the lower and upper bounds of the $95 \% \mathrm{CI}]$ for men when compared to women [16.9\%; 95\% CI (15.4; 18.4); $\mathrm{P}<0.001]$. Other factors that could influence the metastatic prognosis, include mitotic rate, vascular invasion, the number of tumor-infiltrating lymphocytes (5), regression and the immunological mechanisms behind it $(5,9)$, genetic (5) or neuroendocrine factors, although the latter are being studied in nonmelanoma skin cancer (10).

The principles of staging and managing patients with melanoma were updated in 2021 by the National Comprehensive Cancer Network (NCCN) (11). Histopathologically, the Breslow index, which represents the depth of a melanoma lesion from the cutaneous surface (granulous layer) to its deepest point, is one of the most important prognostic factors for metastases (6,7). Tumor stages of TNM classification are based on this Breslow index and ulceration detected histopathologically (11). According to the Breslow index, thin lesions are $\leq 1 \mathrm{~mm}$ thickness, so-called intermediate lesions vary from 1.01-4 mm thickness, whereas thick lesions are $>4 \mathrm{~mm}$ thickness (11). Calomarde-Rees et al revealed an HR of at least 11.1 higher if Breslow was $>2 \mathrm{~mm}$ [95\% CI (4.2-29.4); $\mathrm{P}<0.001]$ in developing hematogenous metastases and an HR of 8.5 higher [95\% CI (4.3-16.8); $\mathrm{P}<0.001]$ of developing lymphatic metastases (5). Furthermore, they reported an HR of at least 9.3 higher if Breslow was $>4 \mathrm{~mm}$ to develop hematogenous metastasis [95\% CI $(3.5 ; 24.6)$; $\mathrm{P}<0.001]$ and an HR of 5.4 higher to develop lymphatic metastasis [95\% CI $(2.4 ; 12.4) ; \mathrm{P}<0.001]$.

The first lymph node involved in the metastatic process is known as the sentinel lymph node $(12,13)$. Its implication is the most important prognostic factor of metastatic involvement of the other regional nodes (14). In addition, the staging, treatment and follow-up differ with the status of the sentinel lymph node (11). The sentinel lymph node can be detected using intradermally injected tracers near the site of the scar during an excisional biopsy of the primary lesion (or an incisional biopsy in case of a large primary tumour or special location of the tumour, such as the face, ear or acral site), or during the wide local excision (WLE) procedure. The tracers migrate via lymphatic vessels towards the sentinel lymph node, allowing adequate identification and enabling sentinel lymph node biopsy (SLNB) $(15,16)$. Identification of the sentinel lymph node is achieved by lymphoscintigraphy or single positron emission computed tomography/computed tomography (SPECT/CT), the latter being superior to planar imaging in the number, anatomical localization and presence near the injection site of the sentinel lymph nodes detected $(17,18)$.

Only a few studies published in the scientific literature have evaluated the prognostic factors of metastasis in melanoma patients; the interest being driven towards metastasis in the sentinel lymph node as a particular location (19-23) and towards prognostic factors of overall or melanoma-specific survival $(14,24,25)$.

The primary objective of the present study was to evaluate the association between age, sex, tumor localization or histopathological characteristics and the risk of developing metastasis (overall and by type of spread) in cutaneous melanoma patients. The secondary objective was to assess the risk for positive sentinel lymph nodes.

\section{Materials and methods}

Study design and setting. An observational, longitudinal, retrospective cohort study was conducted on patients diagnosed with melanoma from January 2008 to December 2017, at the Department of Dermatology, County Emergency Hospital Cluj-Napoca (Cluj-Napoca, Romania), a regional tertiary medical centre. The investigated data were collected from the medical charts, and in our statistics only the patients that had received medical care from the physicians involved in the present study were included. Patients provided informed consent for the use of their data. The present study was approved by the Ethics Committee of the 'Iuliu Hațieganu' University of Medicine and Pharmacy (approval no. 106 from April 15, 2019) and also by the County Emergency Hospital Cluj-Napoca (approval no. 14233/22.05.2020).

Participants. A total of 143 patients aged 18 to 84 years with cutaneous melanoma lesions, having a SPECT/CT or lymphoscintigraphic examination, and a histopathological result for the melanoma lesions and sentinel lymph nodes were eligible for the study. Patients with non-cutaneous melanoma and patients who were treated by physicians who did not agree with their inclusion in the study were excluded.

Outcomes and predictors. The primary outcome of the present study was the metastasis status over time (e.g., present/absent). Over time metastasis was defined as any metastasis identified no earlier than 6 months from the diagnosis and confirmed histopathologically (when possible) and by imaging methods alone (when histopatology was not possible). The type of metastasis (e.g., metastasis by lymphatic or hematogenous pathway, each defined as present/absent), and the sentinel lymph node status (defined as positive or negative) were the secondary outcomes.

The following predictors were evaluated: The sex, the age at diagnosis, the primary lesion location (classified by the four regions: Head and neck, trunk (implies truncal, abdominal, or pelvic sites), upper limbs and lower limbs), Breslow index, the presence of ulceration (collected from the histopathological report), the presence and type of metastasis, the presence of a positive sentinel lymph node, as well as the number and localization of sentinel lymph nodes. The histopathological evaluation was performed by the same doctor, a pathologist experienced in melanocytic neoplasms with a standard checklist report (26). Data of the thickest lesion was used whenever more than one lesion was present in the same patient. Lymphatic metastases were evaluated over time and included in-transit metastases, regional or distant lymph node metastases detected by ultrasound, and confirmed histopathologically from 6 months to 9 years from WLE and/or elective lymph node dissection (ELNB). Hematogenous metastasis was considered as local recurrence and distant metastasis to any other location that did not involve lymphatic sites mentioned before, that appeared in time (from 6 months to 9 years from diagnosis) and was detected on follow-up imaging. Not all of the distant metastases had a histopathological confirmation due to absolute imagistic evidence or impossibility to obtain a biopsy (due to logistics, site, or refusal of the patient). 
Statistical analysis. The binomial logistic regression analysis was used to identify predictors independently associated with melanoma metastasis, types of metastasis, and positivity of sentinel lymph nodes. The effects of each predictor on the primary and secondary outcomes were expressed as crude odds ratio (OR) with their $95 \% \mathrm{CI}$ (values provided in square brackets in the Tables I-IV).

Descriptive statistics including the mean \pm standard deviation, median and interquartile range (IQR) and frequency (\%) were used to describe the continuous and nominal/ordinal variables. Chi-square (with or without correction) or Fisher's exact test was used to assess whether nominal predictors had different distributions for the metastasis vs. non-metastasis groups, lymphatic metastasis vs. non-lymphatic metastasis groups and bloodstream metastasis vs. non-bloodstream metastasis groups. Student's t-test or Mann-Whitney test were used to identify significant differences in distributions of continuous variables on the aforementioned groups.

All statistical analysis was performed with IBM SPSS Statistics for Windows program (version 25.0; IBM Corp.). $\mathrm{P}<0.05$ was considered to indicate a statistically significant difference.

\section{Results}

Patient characteristics. A total of 143 patients aged 18 to 84 years were included in the present study, specifically, 65 men (45\%) and 78 women (55\%). The demographic, clinical, and histopathological characteristics of the studied patients are provided in Table I.

Lesion characteristics. The most common primary lesion localization was the trunk (including the thorax, abdomen or pelvis), followed by the inferior limbs (including the buttocks as well as the toes), the superior limbs (including the shoulders and fingers) and fewer lesions were located in the region of the head and neck (Table I).

Hematogenous metastases over time were located in the lungs (24.5\% of all metastases), brain (12.2\%), liver (10.2\%) and a few were also located in the bone (6.1\%), spleen (2\%) and adrenal glands (2\%), whereas $4.1 \%$ represented local recurrence (data not shown).

The demographic, clinical, and histopathological variables stratified by type of metastasis are presented in Table II. The results of the bivariate analysis revealed that metastasis over time by lymphatic pathway and metastasis by hematogenous pathway were significantly associated with the presence of ulceration and the presence and number of positive sentinel lymph nodes. Neither metastasis by lymphatic pathway, nor hematogenous spread metastasis were associated with sex, age, or anatomic localization $(\mathrm{P}>0.05)$.

Univariate logistic regression analysis identified the presence of ulceration and the number of positive sentinel lymph nodes as independent risk factors of metastasis and metastasis type in patients with cutaneous melanoma (Table III). Concurrently, Breslow's thickness in millimeters was an independent predictor only for metastasis by the hematogenous pathway $(\mathrm{P}<0.05)$. Patients with a Breslow thickness between 2-4 $\mathrm{mm}$ had a 5.7 -fold higher risk for metastasis and a 4.2 -fold higher risk for metastasis by the hematogenous pathway
Table I. Characteristics of the patients

\begin{tabular}{lc}
\hline Variables & $\begin{array}{c}\text { All samples } \\
(\mathrm{n}=143)\end{array}$ \\
\hline $\begin{array}{l}\text { Age, years } \\
\text { Sex }\end{array}$ & $56[41 ; 64]$ \\
Male & \\
Anatomic localization & \\
Trunk & $65(45.5)$ \\
Lower limbs & \\
Upper limbs & $59(41.3)$ \\
Head and Neck & $46(32.2)$ \\
Breslow thickness, mm (continuous) $)^{\mathrm{a}}$ & $25(17.5)$ \\
Breslow thickness, mm (categorical) ${ }^{\mathrm{b}, \mathrm{c}}$ & $13(9.1)$ \\
$\leq 1.00$ & $2.2[1.5 ; 3.0]$ \\
$1.01-2.00$ & $10(7.0)$ \\
$2.01-4.00$ & $52(36.4)$ \\
$>4.00$ & $64(44.8)$ \\
Ulceration, yes ${ }^{\mathrm{b}}$ & $17(11.9)$ \\
Sentinel lymph node status ${ }^{\mathrm{b}, \mathrm{d}}$ & $60(42.0)$ \\
Positive & \\
Number of positive sentinel lymph nodes ${ }^{\mathrm{b}, \mathrm{d}}$ & $31(21.7)$ \\
0 & $112(78.3)$ \\
1 & $21(14.7)$ \\
$\geq 2$ & $10(7.0)$ \\
\hline
\end{tabular}

${ }^{a}$ Numerical summaries were expressed as the median and interquartile range [Q1; Q3]; Q1=first quartile; Q3=third quartile. ${ }^{\text {N Numerical }}$ summaries were absolute (number) and relative frequencies (\%). 'Two patients diagnosed with in situ melanoma. ${ }^{\mathrm{d} D a t a}$ were missing for 5 patients. $n$, number of patients.

(Table III). Age $\geq 55$ years, sex, and anatomic localization were not statistically significantly associated neither with the presence nor with the type of metastasis $(\mathrm{P}>0.05)$.

Univariate logistic regression analysis identified male sex and the presence of ulceration as independent risk factors for the positivity of sentinel lymph nodes in patients with cutaneous melanoma (Table IV).

\section{Discussion}

The results revealed that some of the evaluated predictors influence the presence of all types of metastases. Some factors, but not all, influence the presence of lymphatic spread metastases over time (such as ulceration and positive sentinel lymph node), and certain of them do influence the presence of hematogenous spread metastases in time (such as Breslow index, ulceration, and positive sentinel lymph nodes). Male sex and the presence of ulcerations were demonstrated as significant predictors for positive sentinel lymph nodes.

Cherobin et al (7) also revealed that male sex, nodular melanoma, a Breslow $>1 \mathrm{~mm}$, and the presence of ulceration were factors that increased the risk of metastasis of any type, lymphatic or hematogenous. 


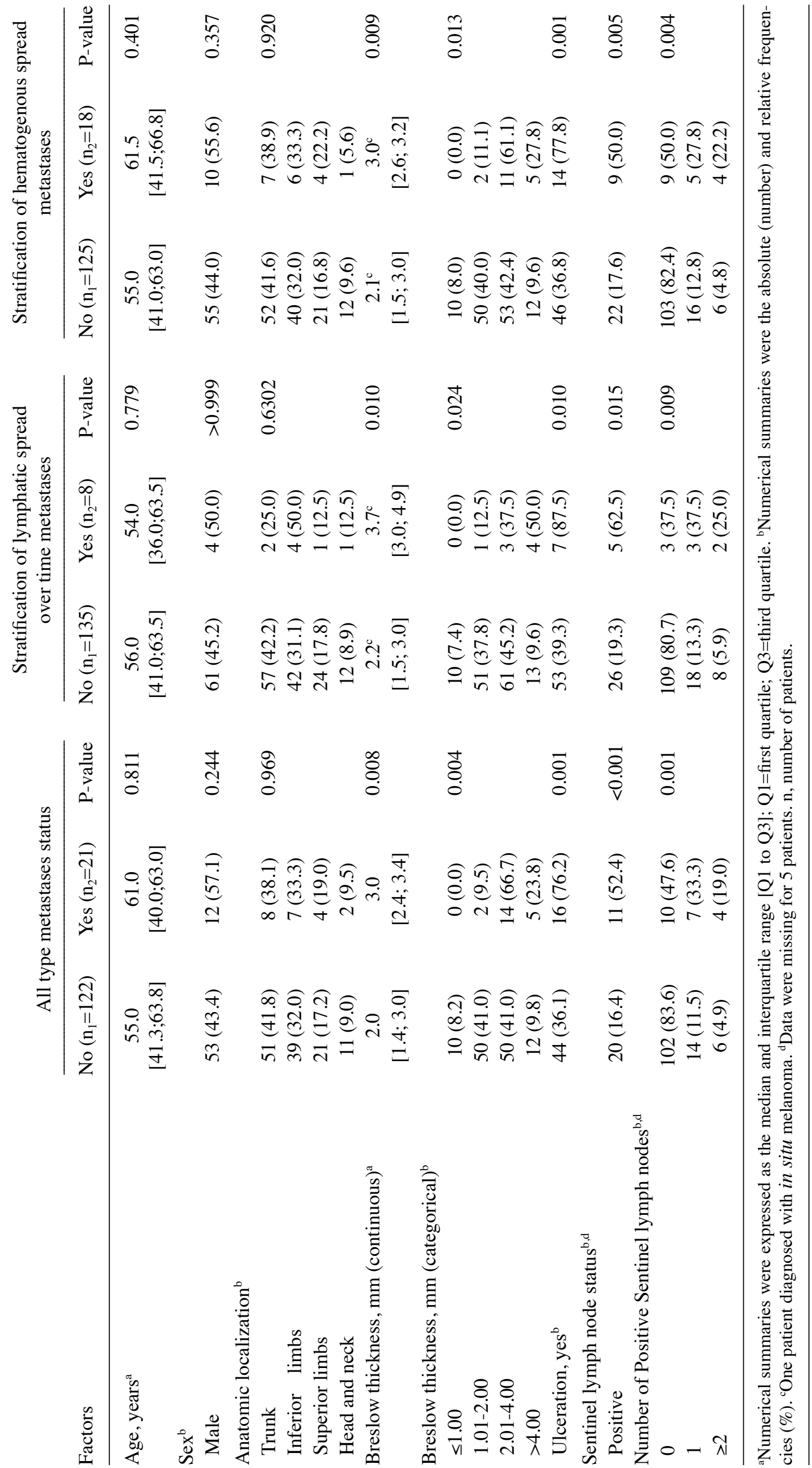


Table III. Logistic regression models for metastatic risk in patients with cutaneous melanoma.

\begin{tabular}{|c|c|c|c|}
\hline & $\begin{array}{c}\text { All type of } \\
\text { metastasis status }\end{array}$ & $\begin{array}{c}\text { Stratification of } \\
\text { lymphatic spread } \\
\text { over time metastasis }\end{array}$ & $\begin{array}{l}\text { Stratification of } \\
\text { hematogenous } \\
\text { spread metastasis }\end{array}$ \\
\hline Variables & Crude OR $[95 \% \mathrm{CI}]$ & Crude OR [95\% CI] & Crude OR $[95 \% \mathrm{CI}]$ \\
\hline \multicolumn{4}{|l|}{ Age, years } \\
\hline$<55$ & 1 [Reference] & 1 [Reference] & 1 [Reference] \\
\hline$\geq 55$ & $1.29[0.50 ; 3.28]$ & $0.93[0.22 ; 3.87]$ & $1.55[0.56 ; 4.25]$ \\
\hline \multicolumn{4}{|l|}{ Sex } \\
\hline Female & 1 [Reference] & 1 [Reference] & 1 [Reference] \\
\hline Male & $1.73[0.68 ; 4.42]$ & $1.21[0.29 ; 5.05]$ & $1.59[0.59 ; 4.30]$ \\
\hline \multicolumn{4}{|c|}{ Anatomic localization } \\
\hline Trunk & 1 [Reference] & 1 [Reference] & 1 [Reference] \\
\hline Lower limbs & $1.14[0.38 ; 3.43]$ & $2.71[0.48 ; 15.52]$ & $1.11[0.35 ; 3.58]$ \\
\hline Upper limbs & $1.21[0.33 ; 4.47]$ & $1.19[0.10 ; 13.73]$ & $1.42[0.38 ; 5.34]$ \\
\hline Head and Neck & $1.16[0.23 ; 6.23]$ & $2.38[0.20 ; 28.36]$ & $0.62[0.07 ; 5.52]$ \\
\hline \multicolumn{4}{|c|}{ Breslow thickness, mm (categorical) } \\
\hline$\leq 2.00$ & 1 [Reference] & 1 [Reference] & 1 [Reference] \\
\hline $2.01-4.00$ & $5.69[1.55 ; 20.93]^{\mathrm{a}}$ & $1.53[0.25 ; 9.45]$ & $4.22[1.12 ; 15.93]^{\mathrm{b}}$ \\
\hline$>4.00$ & $7.39[1.45 ; 37.69]^{\mathrm{a}}$ & $7.75[1.17 ; 51.45]^{\mathrm{b}}$ & $7.39[1.45 ; 37.69]^{\mathrm{a}}$ \\
\hline \multicolumn{4}{|l|}{ Ulceration } \\
\hline Absent & 1 [Reference] & 1 [Reference] & 1 [Reference] \\
\hline Present & $5.67[1.95 ; 16.54]^{\mathrm{a}}$ & $10.83[1.30 ; 90.55]^{\mathrm{a}}$ & $6.01[1.87 ; 19.35]^{\mathrm{a}}$ \\
\hline \multicolumn{4}{|c|}{ No. of positive sentinel lymph nodes } \\
\hline 0 & 1 [Reference] & 1 [Reference] & 1 [Reference] \\
\hline 1 & $5.10[1.67 ; 15.57]^{\mathrm{a}}$ & $6.06[1.13 ; 32.37]^{\mathrm{b}}$ & $3.58[1.06 ; 12.04]^{\mathrm{b}}$ \\
\hline$\geq 2$ & $6.80[1.64 ; 28.19]^{\mathrm{a}}$ & $9.08[1.32 ; 62.45]$ & $7.63[1.81 ; 32.10]^{\mathrm{a}}$ \\
\hline
\end{tabular}

Statistical significance was obtained when $\mathrm{P}<0.05$. The degree of statistical significance was denoted by ${ }^{\mathrm{a}} \mathrm{P}<0.01$ and ${ }^{\mathrm{b}} \mathrm{P}<0.05$. Crude $\mathrm{ORs}$ were obtained by binomial logistic regression analysis. OR, odds ratio; CI, confidence interval.

Metastases differ by timing and type based on sex with women exhibiting more advantages in each of these, as revealed by Mervic (8). The advantages over men consist of a longer period until the appearance of metastases, and the development of loco-regional metastases than distant ones. In the present study, differences between sexes were only found regarding the occurence of a positive sentinel lymph node, men having 2.3-fold higher risk of developing sentinel lymph nodes than women.

In the present study, significant factors associated with the occurrence in time of all types of metastases were a Breslow thickness $>2 \mathrm{~mm}$, the presence of ulceration, the presence of a positive sentinel lymph node, even if only one was affected. In contrast to the study by Calomarde-Rees et al (5), in our study, age, sex and anatomic location were not significantly associated with the presence of metastases overall.

For the independent predictors, the risk for metastases nonetheless was high. If ulceration was present, for example, there was a 5.67-fold higher risk for metastases of any type.

Brauer et al (27) reported that the presence of ulceration and increased Breslow index appeared more often in patients who developed metastasis $<3$ years after complete therapy, whereas the others tended to develop metastases only $>8$ years after complete therapy. In addition, they observed a difference in the prognosis of patients with truncal, head, and neck melanoma, as opposed to those developing lesions on extremities, the latter being less likely to develop metastases (23).

In the present study, the location of the primary lesion was not determined to be a significant factor, considering that localization remains controversial $(7,28)$. Head and neck melanoma was associated with hematogenous metastases (29), but this was neither supported by our results nor by the results of Cherobin et al (7).

As a physiopathological mechanism, there are three models of spread in melanoma metastases, proposed by Morton et al (14), Medalie and Ackerman (30) and Clark (31). The study by Morton et al (14) suggests a sequential spread of metastasis, first lymphatic and then via the bloodstream, after some time. Medalie and Ackerman (30) suggest that metastasis happens both ways concurrently, whereas Clark (31) suggests that there may be lesions that spread only by the lymphatic pathway and others only via the bloodstream.

The risk of lymphatic metastasis over time was increased almost 1.5 -fold if there was more than one sentinel lymph node 
Table IV. Risk factors for sentinel lymph node positivity (regression results).

\begin{tabular}{lc} 
Variable & Crude OR $[95 \% \mathrm{CI}]$ \\
\hline Age groups & \\
$<55$ years & $1[$ Reference $]$ \\
$\geq 55$ years & $0.84[0.38 ; 1.87]$ \\
Sex & \\
Female & $1[$ Reference $]$ \\
Male & $2.27[1.00 ; 5.13]^{\mathrm{a}}$ \\
Anatomic localization & \\
Trunk & $1[$ Reference $]$ \\
Lower limbs & $0.37[0.13 ; 1.03]$ \\
Upper limbs & $0.62[0.20 ; 1.91]$ \\
Head and neck & $0.74[0.18 ; 3.03]$ \\
Breslow thickness, mm (categorical) & \\
$\leq 2.00$ & $1[$ Reference $]$ \\
$2.01-4.00$ & $1.80[0.75 ; 4.34]$ \\
$>4.00$ & $2.70[0.76 ; 9.60]$ \\
Ulceration & \\
Absent & $1[$ Reference $]$ \\
Present & $2.74[1.21 ; 6.22]^{\mathrm{a}}$ \\
\hline
\end{tabular}

Statistical significance was obtained when $\mathrm{P}<0.05$. The degree of statistical significance was denoted by ${ }^{\mathrm{a}} \mathrm{P}<0.05$.

detected at the time of diagnosis. In contrast, the risk of hematogenous spread metastases increased even higher if there was more than one sentinel lymph node detected. This may reveal the fact that once the lymphatic drainage is affected, it is not necessary to have hematogenous dissemination, and could provide more credence to the mechanisms suggested by Morton et al (14) or Clark (31).

Calomarde-Rees et al (5), in a retrospective study, reported the following factors associated with lymphatic spread: Age $>55$ years, the presence of a tumor in the head, neck and acral region, Breslow thickness $>4 \mathrm{~mm}$, or the presence of vascular invasion in the histopathological evaluation.

Breslow index was not identified in our present study as an independent predictor for lymphatic spread metastases, which appear over time, whereas the presence of ulceration, presence of a positive sentinel lymph node (at least one) were independent predictors for lymphatic spread metastases over time.

Breslow $>4 \mathrm{~mm}$, absence of regression, and some genetic mutations were reported as being associated with hematogenous spread (5). In the present study, Breslow thickness $>2 \mathrm{~mm}$, presence of ulceration, presence of at least one positive sentinel lymph node were independent predictors for hematogenous spread metastases.

Local recurrence has been classified as hematogenous recurrence, as the literature suggests (32).

The second objective of our study revealed that the male sex and the presence of ulceration were risk factors for positive sentinel lymph nodes. Tejera-Vaquerizo et al (6) also revealed that male sex, ulceration, lentigo maligna melanoma histopathological type, Breslow thickness $\geq 0.8 \mathrm{~mm}$ and Clark levels IV and V were factors that shortened the disease-free interval, whereas only Breslow thickness and a number of mitoses $\geq 2$ per $\mathrm{mm}^{2}$ were predictive factors of the positive sentinel lymph nodes on patients with thin melanoma.

Sentinel lymph nodes can be a prognostic factor for metastases that appear after a period of time from diagnosis, through the lymphatic system (lymphatic) or through blood (hematogenous); some other factors that can also influence the metastasis to lymph nodes include age and lymphovascular invasion detected histopathologically in melanoma samples, as Egger et al (19) described in a retrospective study on T2 melanoma patients, with data from the National Cancer Database records from 2010 to 2015. An inverse relationship between age and risk of a positive sentinel lymph node and a powerful relationship between the presence of lymphovascular invasion present in the histopathological report and high risk of metastatic lymph nodes were reported by Egger et al (19). Other studies revealed that age was also a predictive factor for sentinel lymph node metastatic invasion $(28,33)$.

In our study, age was not revealed to be a predictive factor for positive sentinel lymph nodes, however the male sex exhibited a 2.27-fold higher risk of having a positive sentinel lymph node at diagnosis than the female sex. Ulceration exhibited a 2.74-fold higher risk of having a positive sentinel lymph node as well. White et al (34) revealed an association between trunk melanoma and metastasis to the sentinel lymph nodes, whereas Callender et al (35) found that primary melanomas of the upper limbs were thinner and had the best survival rate, with a possible explanation being that these lesions are in a more exposed area, visible for inspection of patients which present earlier to the dermatologist.

A limitation of the present study was that it was conducted in a single tertiary care hospital, thus, the external validity of the assessed patients may be limited. Wide confidence intervals that can be explained by the presence of few events relative to candidate predictors were also observed. The results were statistically significant, however, their significance should be interpreted with caution. As with any observational study, unobserved confounding variables are known to be a threat to the internal validity of a study.

Another limitation of the present study was the small number of patients without metastases, having thin $(8.2 \%)$ and thick $(9.8 \%)$ melanoma, with the majority of patients having lesions with a Breslow index between 1.01 and $4.00 \mathrm{~mm}(82 \%)$. The same issue stands for patients with metastases and thin melanoma (0\%), thick melanoma (23.8\%) and intermediate melanoma $(76.2 \%)$, with the majority of patients $(66.7 \%)$ having lesions between 2.01-4.00 mm. Despite these factors, the results were statistically significant. Therefore, due to the distribution of the characteristics of patients, the risk of having a lesion $>1 \mathrm{~mm}$, as opposed to those having lesions $<1 \mathrm{~mm}$, was not feasible in our study due to the small number of patients that fit the latter criterion.

The present results were statistically significant, reinforcing the results previously published in scientific literature.

It is important to know which factors influence each type of metastasis, since this affects the follow-up of the patients. Knowledge of the factors that influence the type of metastasis could help with individual healthcare management 
options, saving time in orienting the treatment and follow-up of a patient.

In conclusion, Breslow index, ulceration, and positive sentinel lymph nodes were demonstrated as significant factors for hematogenous metastases, whereas only ulceration and positive sentinel lymph nodes were significant for lymphatic metastases over time. In addition, ulceration and male sex were revealed to be prognostic factors for positive sentinel lymph nodes.

\section{Acknowledgements}

Not applicable.

\section{Funding}

No funding was received.

\section{Availability of data and materials}

The datasets used and/or analyzed during the current study are available from the corresponding author on reasonable request.

\section{Authors' contributions}

ASB, GC, SCS, CIB, GD, CMS, LR made substantial contributions to conception and design, as well as the acquisition and interpretation of the data. ASB, DCL, TCD, SDB made substantial contributions to conception and design, as well as the analysis and interpretation of the data. All authors were involved in drafting the manuscript or revising it critically for important intellectual content, and provided final approval of the version to be published.

\section{Ethics approval and consent to participate}

Patients provided informed consent for the use of their data. The present study was approved by the Ethics Committee of the 'Iuliu Hațieganu' University of Medicine and Pharmacy (approval no. 106 from April 15, 2019) and also by the County Emergency Hospital Cluj-Napoca (approval no. $14233 / 22.05 .2020)$.

\section{Patient consent for publication}

Not applicable.

\section{Competing interests}

The authors declare that they have no competing interests.

\section{References}

1. Swetter SM and Elston DM: Cutaneous Melanoma. Medscape, pp1-35, 2019.

2. Rocken M, Schaller M, Sattler E and Burgdorf W: Color atlas of dermatology. Thieme, Stuttgart, pp256-261, 2012.

3. Ferlay J, Ervik M, Lam F, Colombet M, Mery L, Piñeros M, Znaor A, Soerjomataram I and Bray F: Global Cancer Observatory: Cancer Today. International Agency for Research on Cancer, Lyon, 2020.
4. Rotaru M, Jitian CR and Iancu GM: A 10-year retrospective study of melanoma stage at diagnosis in the academic emergency hospital of Sibiu county. Oncol Lett 17: 4145-4148, 2019.

5. Calomarde-Rees L, García-Calatayud R, Requena Caballero C, Manrique-Silva E, Traves V, García-Casado Z, Soriano V, Kumar R and Nagore E: Risk factors for lymphatic and hematogenous dissemination in patients with stages I to II cutaneous melanoma. JAMA Dermatol 155: 679-687, 2019.

6. Tejera-Vaquerizo A, Ribero S, Puig S, Boada A, Paradela S, Moreno-Ramírez D, Cañueto J, de Unamuno B, Brinca A, Descalzo-Gallego MA, et al: Survival analysis and sentinel lymph node status in thin cutaneous melanoma: A multicenter observational study. Cancer Med 8: 4235-4244, 2019.

7. Cherobin AC, Wainstein AJ, Colosimo EA, Goulart EM and Bittencourt FV: Prognostic factors for metastasis in cutaneous melanoma. An Bras Dermatol 93: 19-26, 2018.

8. Mervic L: Time course and pattern of metastasis of cutaneous melanoma differ between men and women. PLoS One 7: e32955, 2012.

9. Zurac S, Neagu M, Constantin C, Cioplea M, Nedelcu R, Bastian A, Popp C, Nichita L, Andrei R, Tebeica T, et al: Variations in the expression of TIMP1, TIMP2 and TIMP3 in cutaneous melanoma with regression and their possible function as prognostic predictors. Oncol Lett 11: 3354-3360, 2016.

10. Lupu M, Caruntu A, Caruntu C, Papagheorghe LML, Ilie MA, Voiculescu V, Boda D, Constantin C, Tanase C, Sifaki M, et al: Neuroendocrine factors: The missing link in non-melanoma skin cancer (Review). Oncol Rep 38: 1327-1340, 2017.

11. Swetter SM, Thompson JA, Albertini MR, Barker CA, Baumgartner J, Boland G, Chmielowski B, DiMaio D, Durham A, Fields RC, et al: Melanoma: Cutaneous, Version 2.2021, NCCN Clinical Practice Guidelines in Oncology, pp1-225, 2021.

12. Thompson JF, McCarthy WH, Bosch CM, O'Brien CJ, Quinn MJ, Paramaesvaran S, Crotty K, McCarthy SW, Uren RF and Howman-Giles R: Sentinel lymph node status as an indicator of the presence of metastatic melanoma in regional lymph nodes. Melanoma Res 5: 255-260, 1995.

13. Krengel S, Hauschild A and Schäfer T: Melanoma risk in congenital melanocytic naevi: A systematic review. Br J Dermatol 155: $1-8,2006$.

14. Morton DL, Thompson JF, Cochran AJ, Mozzillo N, Nieweg OE, Roses DF, Hoekstra HJ, Karakousis CP, Puleo CA, Coventry BJ, et al: Final trial report of sentinel-node biopsy versus nodal observation in melanoma. N Engl J Med 370: 599-609, 2014

15. Swerdlow AJ, English JS and Qiao Z: The risk of melanoma in patients with congenital nevi: A cohort study. J Am Acad Dermatol 32: 595-599, 1995.

16. Clark WH Jr, Elder DE, Guerry D IV, Epstein MN, Greene MH and Van Horn M: A study of tumor progression: The precursor lesions of superficial spreading and nodular melanoma. Hum Pathol 15: 1147-1165, 1984.

17. Grob JJ, Gaudy-Marqueste G, Kha KB, Johnson TM,Durham AB Dummer R and Goldinger SM: Melanoma. In: Rooks Textbook of Dermatology. Griffiths CEM, Barker J, Bleiker T, Chalmers R and Creamer D (eds). John Wiley \& Sons Ltd., Chinchester, pp3973-4008, 2016.

18. Wagner T, Buscombe J, Gnanasegaran G and Navalkissoor S: SPECT/CT in sentinel lymph node imaging. Nucl Med Commun 34: 191-202, 2013.

19. Egger ME, Stevenson M, Bhutiani N, Jordan AC, Scoggins CR, Philips P, Martin RCG II and McMasters KM: Age and lymphovascular invasion accurately predict sentinel lymph node metastasis in T2 melanoma patients. Ann Surg Oncol 26: 3955-3961, 2019.

20. Jaukovic L, Rajović M, Kandolf Sekulovic L, Radulovic M, Stepic N, Mijuskovic Z, Petrov N and Ajdinovic B: Time to procedure, nuclear imaging and clinicopathological characteristics as predictive factors for sentinel lymph node metastasis in cutaneous melanoma: A single-center analysis. Ann Plast Surg 81: 80-86, 2018.

21. Munsch C, Lauwers-Cances V, Lamant L, Gentil C, Rochaix P, Garrido I, Lopez R, Chevreau C, Paul C and Meyer N: Breslow thickness, clark index and ulceration are associated with sentinel lymph node metastasis in melanoma patients: A cohort analysis of 612 patients. Dermatology 229: 183-189, 2014.

22. White RL Jr, Ayers GD, Stell VH, Ding S, Gershenwald JE, Salo JC, Pockaj BA, Essner R, Faries M, Charney KJ, et al: Factors predictive of the status of sentinel lymph nodes in melanoma patients from a large multicenter database. Ann Surg Oncol 18: 3593-3600, 2011. 
23. Cordeiro E, Gervais MK, Shah PS, Look Hong NJ and Wright FC: Sentinel lymph node biopsy in thin cutaneous melanoma: A systematic review and meta-analysis. Ann Surg Oncol 23: 4178-4188, 2016.

24. Karakousis G, Gimotty PA, Bartlett EK, Sim MS, Neuwirth MG, Fraker D, Czerniecki BJ and Faries MB: Thin melanoma with nodal involvement: Analysis of demographic, pathologic, and treatment factors with regard to prognosis. Ann Surg Oncol 24: 952-959, 2017.

25. Abdel-Rahman O: Clinical correlates and prognostic value of different metastatic sites in patients with malignant melanoma of the skin: A SEER database analysis. J Dermatolog Treat 29: 176-181, 2018

26. Protocol for the examination of specimens from patients with melanoma of the skin. College of American Pathologists, 2011. Available from: http://www.cap.org/apps/docs/committees/cancer/cancer_ protocols/2011/SkinMelanoma_11protocol.pdf.

27. Brauer JA, Wriston CC, Troxel AB, Elenitsas R, Shin DB, Guerry D and Ming ME: Characteristics associated with early and late melanoma metastases. Cancer 116: 415-423, 2010.

28. Sinnamon AJ, Neuwirth MG, Yalamanchi P, Gimotty P, Elder DE, $\mathrm{Xu}$ X, Kelz RR, Roses RE, Chu EY, Ming ME, et al: Association between patient age and lymph node positivity in thin melanoma. JAMA Dermatol 153: 866-873, 2017.

29. Cohn-Cedermark G, Månsson-Brahme E, Rutqvist LE, Larsson O, Singnomklao T and Ringborg U: Metastatic patterns, clinical outcome, and malignant phenotype in malignant cutaneous melanoma. Acta Oncol 38: 549-557, 1999.
30. Medalie N and Ackerman AB: Sentinel node biopsy has no benefit for patients whose primary cutaneous melanoma has metastasized to a lymph node and therefore should be abandoned now. Br J Dermatol 151: 298-307, 2004.

31. Clark WH: Tumour progression and the nature of cancer. Br J Cancer 64: 631-644, 1991.

32. Heenan PJ: Local recurrence of melanoma. Pathology 36: 491-495, 2004

33. Conic RRZ, Ko J, Damiani G, Funchain P, Knackstedt T, Vij A, Vidimos A and Gastman BR: Predictors of sentinel lymph node positivity in thin melanoma using the national cancer database. J Am Acad Dermatol 80: 441-447, 2019.

34. White RL Jr, Ayers GD, Stell VH, Ding S, Gershenwald JE, Salo JC, Pockaj BA, Essner R, Faries M, Charney KJ, et al: Factors predictive of the status of sentinel lymph nodes in melanoma patients from a large multicenter database. Ann Surg Oncol 18: 3593-3600, 2011.

35. Callender GG, Egger ME, Burton AL, Scoggins CR, Ross MI, Stromberg AJ, Hagendoorn L, Martin RC II and McMasters KM: Prognostic implications of anatomic location of primary cutaneous melanoma of $1 \mathrm{~mm}$ or thicker. Am J Surg 202: 659-665, 2011.

(i)(9) This work is licensed under a Creative Commons International (CC BY-NC-ND 4.0) License. 